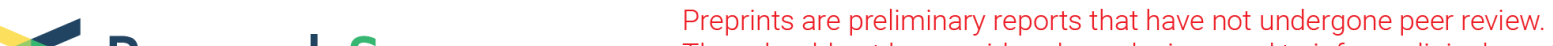 $\begin{array}{ll}\text { Research Square } & \text { They should not be considered conclusive, used to inform clinical practice, } \\ \text { or referenced by the media as validated information. }\end{array}$
}

\section{The Association Between Alpha-7 Nicotinic Acetylcholine Receptor and Microglial Polarization in Spinal Cord Injury: Nicotine as an Alternative Therapy for Neuroinflammation}

\section{Abolfazl Badripour}

Tehran University of Medical Sciences School of Medicine

Kamyar Moradi

Tehran University of Medical Sciences School of Medicine

\section{Zahra Ebrahim Soltani}

Tehran University of Medical Sciences School of Medicine

\section{Sayna Bagheri}

Tehran University of Medical Sciences School of Medicine

\section{Pasha Reza Shams Azar}

Tehran University of Medical Sciences School of Medicine

\section{Shiva Hashemizadeh}

Tehran University of Medical Sciences School of Medicine

\section{Mohammad Mahdi Khavandi}

Tehran University of Medical Sciences School of Medicine

\section{Marzieh Khavandi}

University of Waterloo School of Pharmacy

\section{Seyed Mohsen Ahmadi}

Tehran University of Medical Sciences School of Medicine

Ahmad Reza Dehpour ( $\nabla$ dehpour@yahoo.com )

Experimental Medicine Research Center, Tehran University of Medical Sciences, Tehran, Iran https://orcid.org/0000-0002-8001-5565

\section{Research}

Keywords: Apha-7 nicotinic acetylcholine receptor (a7 nAChR), Microglia, Neuroinflammation, Nicotine, Spinal cord injury (SCl)

Posted Date: October 2nd, 2020

DOI: https://doi.org/10.21203/rs.3.rs-84478/v1 
License: (c) (i) This work is licensed under a Creative Commons Attribution 4.0 International License. Read Full License 


\section{Abstract}

Background: Nicotine is an agonist of alpha-7 nicotinic acetylcholine receptor ( $a 7 \mathrm{nAChR}$ ). The association between the expression of a7 nAChR and neuroinflammation has been extensively reported. Herein, we assessed the efficacy of Nicotine in the management of spinal cord injury (SCl) complications and mediating mechanisms.

Methods: In this study, 64 male rats were randomly allocated to $7 \mathrm{SCl}$ and a sham-operated groups. SCl was induced through an aneurysmal clip at the T9/T10 level. The group list consists of a non-treated group as the control, four Nicotine-treated groups receiving $0.5,1,1.5$, and $3 \mathrm{mg} / \mathrm{kg}$ of the drug, a Methyllycaconitine (MLA, $1.5 \mathrm{mg} / \mathrm{kg}$ )-treated group, a group of rodents receiving MLA plus the most effective dosage of Nicotine, and a sham one. Locomotion and mechanical allodynia were assessed during 28 days using the Basso, Beattie, Bresnahan (BBB) and von Frey methods, respectively. In the end, spinal cord samples were taken to assess cavity formation, the expression levels of $M 1$ and $M 2$ macrophages, pro-inflammatory and anti-inflammatory factors, as well as a7 nAChR and NF-kB gene levels.

Results: Repeated measures analysis revealed significant effect of time-treatment interaction on locomotion $[F(42,336)=120.2, p<0.001]$ and mechanical sensitivity $[F(35,280)=45.47, p<0.001]$. Behavioral response to Nicotine was dose-dependent, and $1 \mathrm{mg} / \mathrm{kg}$ of this reagent was the most efficient dosage. H\&E staining represented lesser histopathological disruptions in Nicotine-treated animals. SCI increased the M1/M2 ratio $(p<0.001)$ via shifting macrophages polarization towards M1 subset and 1 $\mathrm{mg} / \mathrm{kg}$ of Nicotine could attenuate this ratio $(p<0.001)$ through reversing the shift. Meanwhile, Nicotine administration resulted in a significant elevation of $a 7 \mathrm{nAChR}$ and a reduction of NF-kB genes. Finally, in the Nicotine group, there were declines in the levels pro-inflammatory biomarkers, including TNF- $\alpha$, IL-1 $\beta$, and IL-6, while IL-10 was found higher than the control group ( $p$ values $<0.05$ ). MLA-treated groups showed almost none of the aforementioned alterations.

Conclusion: Single-dose therapy with Nicotine could improve locomotor and sensory complications of $\mathrm{SCl}$. Nicotine possible mechanism of action is through increasing the a7 nAChR level, which alleviates neuro-inflammation by changing microglial phenotyping.

\section{Introduction}

Spinal cord injury (SCl) is still considered as a significant and life-long condition after a broad spectrum of studies because of its complex pathogenesis and the following probable motor and sensory complications that may have negative effects on patient's quality and expectancy of life. These adverse effects are mostly continuous due to the incomplete rehabilitation of the central nervous system (CNS). $\mathrm{SCl}$ has an estimated annual incidence of 12.1-57.8 cases per million worldwide [1]. SCI has two different phases of injury. The primary phase of SCl occurs at the moment of spinal trauma and is described as mechanical damage while the second phase is defined as the following biochemical and 
pathological changes after the injury that worsens by the passage of time. Neuroinflammation plays a fundamental role in the latter phase where dysregulation in the activity of several immune cells such as neutrophils, monocyte-derived macrophages, and resident microglia leads to an imbalance between proinflammatory and anti-inflammatory mediators [2].

The macrophages polarization paradigm refers to the phenotyping of macrophages in response to various exogenous and endogenous stimulants and has two main subsets. M1 macrophages are responsible for the release of pro-inflammatory factors that bring about neurodegenerative effects, while M2 macrophages have neuroprotective characteristics due to its stimulatory impact on anti-inflammatory responses. Therefore, it is not surprising that a higher ratio of $\mathrm{M} 1 / \mathrm{M} 2$ macrophages is accompanied by the dysfunction in the CNS repair, and neurotoxicity [3]. This phenomenon occurs in the second phase of $\mathrm{SCl}$ and notably impairs the patient's locomotor and sensory rehabilitation. In this manner, several previous studies of $\mathrm{SCl}$ have pharmacologically targeted the relative proportions of $\mathrm{M} 1$ and $\mathrm{M} 2$ markers to manage the neuroinflammation [4].

The alpha-7 nicotinic acetylcholine receptor ( $\mathrm{a} 7 \mathrm{nAChR})$ is a member of the nicotinic acetylcholine receptors family, recognized for its diverse roles within the nervous system $[5,6]$. It has been shown that a7 nAChR participates in the modulation of neuroinflammatory processes and therefore, has been of great interest. Nicotine, which is a potent agonist of a7 nAChR, has shown significant effectiveness in terms of $\mathrm{SCl}$ behavioral (i.e., locomotor dysfunction) and molecular deficits (i.e., neuroinflammation). It is hypothesized that the $\mathrm{a} 7 \mathrm{nAChR}$ level affects the microglial polarization within the CNS via the nuclear factor-kappa b (NF-KB) signaling pathway. This issue has been confirmed by several studies of cerebral brain injury [6-8]. Nevertheless, as far as we know, this is the first study that evaluates the association between a7 nAChR, NF-KB, microglial polarization, neuroinflammation, and behavioral recovery in an $\mathrm{SCl}$ setting.

The discovery of novel therapeutic reagents for the treatment of $\mathrm{SCl}$ motor and sensory complications seems necessary due to limited available medications. Up to now, the beneficial effects of a few numbers of drugs have been reported on adverse events of SCl, acting via changing the microglial polarization at the lesion region $[9,10]$. The therapeutic effects of Nicotine have also been mentioned in SCl; however, its exact mechanism of action warrants further investigation [11]. In the present study, we determined to present a novel pathway in $\mathrm{SCl}$ by apprehending the role of a7 nAChR in neuroinflammation and behavioral recovery after $\mathrm{SCl}$.

\section{Materials And Methods}

\section{Study population}

Sixty-four male Wistar rats, weighing 240-300 g, were provided from Tehran Pasteur Institute and were housed in separate cages that were equipped with free access to a sufficient amount of tap water and chow pellets. The room temperature was $23 \pm 2{ }^{\circ} \mathrm{C}$ with $50 \pm 5 \%$ humidity and a 12-hours light/dark cycle. 
The study protocol was executed in agreement with the National Institutes of Health $(\mathrm{NIH})$ Guide for the Care and Use of laboratory animals (NIH publication No. 86 - 23, Eighth Ed.) and institutional and governmental concerns for animal care and use (Approval ID: IR.TUMS.MEDICINE.REC.1398.922). All possible efforts were made to minimize the study population and their suffering.

\section{Drugs}

Nicotine and Methyllycaconitine (MLA) were obtained from Sigma, St Louis, Missouri. Ketamine $\mathrm{HCl}$ (Gedeon Richter Ltd, Budapest, Hungary) and Xylazine $\mathrm{HCl}$ (Bayer, Leverkusen, Germany) were also purchased. Drugs were dissolved in physiologic saline and used through intraperitoneal injection.

\section{Study groups}

In a randomized setting, animals were assigned 8 to equal groups. Four groups received Nicotine (SigmaAldrich, St. Louis, Missouri, United States) in the doses of $0.5,1,1.5$, and $3 \mathrm{mg} / \mathrm{kg}$ in the attempt of identifying the amount with optimal behavioral outcomes, including locomotion and neuropathic pain recovery. $1.5 \mathrm{mg} / \mathrm{kg}$ of MLA was administered to one group while another group received the optimum dosage of Nicotine in addition to $1.5 \mathrm{mg} / \mathrm{kg}$ of MLA. The control and sham-operated groups merely received vehicle (saline $0.9 \%$ ). All groups were followed for 28 days after surgery. All data, including lab tests, locomotor, and sensory evaluations were collected by different observers, blinded to groups. All drugs were intraperitoneally administered 30 min prior to the surgery.

\section{Surgical procedure}

A combination of $86 \mathrm{mg} / \mathrm{kg}$ Ketamine $\mathrm{HCL}$ and $13 \mathrm{mg} / \mathrm{kg}$ Xylazine $\mathrm{HCL}$ was injected intraperitoneally to anesthetize each animal. Dorsal hairs of the rodents were shaved with an electric razor, and the surgical site was cleaned with povidone-iodine. A prophylaxis injection of $30 \mathrm{mg} / \mathrm{kg}$ cefazolin was administered to all rodents before the beginning of the surgery. In the next step, each rat was located on a sterile, heating operating board in a prone position. After posterior midline incision and muscle dissection, complete laminectomy was operated on the T9/T10 vertebrae. The injury was induced on the spinal cord by compression with an aneurysmal clip (YASARGIL $®$ Aneurysm clip system, Titanium mini clips FT712T; closing force, $110 \mathrm{~g}$ [1.08 N]; $4.7 \mathrm{~mm}$ Blade length; $3.8 \mathrm{~mm}$ maximum opening diameter) for 60 seconds. Finally, the wound sites were sutured, and animals were kept in a $35^{\circ} \mathrm{C}$ incubator until recovery. The post-operative care was performed administrating normal saline $(2 \mathrm{ml})$, cefazolin $(20 \mathrm{mg} / \mathrm{kg})$ and buprenorphine $(0.1 \mathrm{mg} / \mathrm{kg})$ for seven successive days. Voiding was performed twice a day manually until complete functional rehabilitation. Of note, the sham group underwent posterior midline incision without the induction of SCl.

\section{Locomotion}

The hindlimb locomotor function was assessed using the Basso, Beattie, Bresnahan (BBB) rating scale in an open field at baseline and on days $1,3,7,14,21$, and 28 after the surgery [12]. For each rat, the BBB score of hindlimbs were averaged and the result was documented. The assessor was blinded to the study groups. Score 21 indicates normal locomotion of hind limbs while 0 accounts for no locomotor function. 


\section{Von Frey}

For each rodent, the withdrawal thresholds of both left and right hind paws were assessed using the simplified up-down (SUDO) method of von Frey testing, which is valid and induces minimal stress to the rodents [13]. The assessments were conducted prior to $\mathrm{SCl}$ induction and on days 7, 14, 21, and 28 of the experiment. First, the rats were habituated to the test platform, which is an elevated box with a netting floor. Then, a series of von Frey hairs (a logarithmic series of 20 calibrated Semmes-Weinstein monofilaments; Stoelting Co., Wood Dale, IL) was smacked from below the platform to the central region of the plantar surface of the rat hind paws and were held for a maximum of 5 seconds. Prominent paw withdrawal or flinch were considered as positive responses. The start point of the test was with filament $10(4.31,2.0 \mathrm{gr})$.

\section{Sample acquisition}

At day 28 post-operation, half of the rats in each group were anesthetized with a mixture of $86 \mathrm{mg} / \mathrm{kg}$ Ketamine HCL and $13 \mathrm{mg} / \mathrm{kg}$ Xylazine HCL and then, $150 \mathrm{ml}$ of phosphate buffered saline (PBS, pH 7.4) was perfused to their heart, followed by $250 \mathrm{ml}$ of formalin-acid picric mixture (4\% paraformaldehyde, $0.4 \%$ picric acid in $0.16 \mathrm{M}$ phosphate buffer, $\mathrm{pH} 7.4$ ) for fixation of the tissues. Three $\mathrm{cm}$ of the spinal cord was selected from the center of the injury site. Specimens were prepared and embedded in paraffin. The paraffinized specimens were sliced into samples with a thickness of 5 micrometers by a Leica 2135 microtome (Deerfield, IL, USA) for Hematoxylin and Eosin (H\&E) and immunohistochemistry (IHC) assays. The other half of the rats underwent spinal cord dissection and the extracted samples were kept inside liquid nitrogen in a $-70^{\circ} \mathrm{C}$ freezer for Enzyme-Linked Immunosorbent Assay (ELISA) and RT-PCR.

\section{Histopathological analysis}

As mentioned above, half of the specimens were stained with Hematoxylin and Eosin (H\&E) dye for histopathological assessment. The staining protocol is completely described in our previous publication [10]. Briefly, after deparaffinization and rehydration of the specimens, the nuclei were stained by rinsing the slides in hematoxylin solution. In the next step, bluing was performed in $0.2 \%$ ammonia water. Then, the slides were counterstained in eosin-phloxine for $1 \mathrm{~min}$ and afterward samples were rinsed in $90 \%$, $96 \%$ and $100 \%$ ethanol for 2 min. Finally, slides were embedded in xylene and mounting medium. The final products were examined using an optical microscope (resolution: 40x) to determine tissue and cavity percentages in the lesion sites.

\section{IHC}

IHC method was performed on half of the spinal cord specimens to evaluate the expression of the surface receptors of M1 and M2 macrophages, which are CD86 and CD206, respectively. The samples were rinsed by $0.1 \mathrm{M}$ PBS in 4 steps. Afterward, in the attempt of retrieving the antigens, sections were placed in 2 normal hydrochloric acid (HCL) solutions for $30 \mathrm{~min}$. Then, the effect of HCL was neutralized by Borate buffer. In the next step, a $3 \%$ solution of Triton X-100 was used for $30 \mathrm{~min}$ to increase the cell 
membranes permeability. Goat serum (10\%) was added as an extra color to the background during a period of 30 min to block nonspecific reaction of the antibodies. Next, a primary antibody (ab220188, Abcam) diluted with PBS (1:100) was added and the combination was transferred to a $2-8{ }^{\circ} \mathrm{C}$ refrigerator for 24 hours. Next, a secondary antibody (ab 182422, Abcam) diluted with PBS (1:150) was added and the processed samples were incubated for 1.5 hours in a $37^{\circ} \mathrm{C}$ incubator. Afterward, 4',6-diamidino-2phenylindole (DAPI) was added in a dim place to counterstain the nuclei. Notably, the samples were washed by PBS between the steps. Finally, the macrophages were calculated, dividing prepared samples into 5 separate areas via an Olympus fluorescent microscope $(\times 400)$ and images were taken from each area. The captured images were analyzed using the ImageJ software (Fiji version) [14]. The result was reported as the percentage of positive immunolabeled cells over the total cells in each selected region (the ratio number of positively stained cells/total number of cells $\times 100$ ).

\section{Real-Time RT-PCR}

Four main phases were conducted for qRT-PCR analysis of a7 nAChR and NF-kB genes expression. First, total RNA was extracted from the specimens using Qiazol reagent (Qiagen, Germany). Second, one microgram of mRNA was reverse transcribed to CDNA according to manufacturer's instructions (Fermentas, USA). Third, an Applied Biosystems 7300 Fast Real-Time PCR System with SYBR green PCR master mix (Applied Biosystems, CA, USA) was employed for real time RT-PCR analysis. The primer sequences are listed in Table 1. The thermocycler conditions were as follows: $95^{\circ} \mathrm{C}$ for $15 \mathrm{~min}$ for activation of DNA polymerase, followed by 45 cycles of amplification at $94^{\circ} \mathrm{C}$ for $15 \mathrm{sec}, 60^{\circ} \mathrm{C}$ for $15 \mathrm{secs}$ and $72^{\circ}$ for $30 \mathrm{sec}$. At last, melting curve analysis was conducted to confirm whether all primers provided a single PCR product. Sequences were normalized with GAPDH as a control. The $2^{-\Delta \Delta C t}$ method was used to measure the relative expression of $a 7$ nAChR.

Table 1

Primers for RT-PCR

\begin{tabular}{|ll}
\hline Gene name & Primers (Forward and reverse) \\
\hline a7 nAChR & F: AAAATGCCTAAGTGGACCAGAA \\
\hline N: TCACTGCAGATCACCTCACTCT \\
\hline F: GTGCAGAAAGAAGACATTGAGGTG \\
\hline RAPDH & F: TCAGAGCAAGAGAGGCATCC \\
\hline & R: GGTCATCTTCTCACGGTTGG \\
\hline
\end{tabular}

Abbreviations: Alpha-7 nicotinic acetylcholine receptor, a7 nAChR; Glyceraldehyde 3-phosphate dehydrogenase, GAPDH; Nuclear factor kappa b, NF-Kb; Reverse transcription polymerase chain reaction (RT-PCR). 
Three pro-inflammatory factors, tumor necrosis factor-alpha (TNF-a), interleukin 1 beta (IL-1 $\beta$ ), and interleukin 6 (IL-6) and an anti-inflammatory mediator, interleukin 10 (IL-10) were measured. The specimens were first homogenized in lysis buffer and then centrifuged for $20 \mathrm{~min}$ at $13,000 \mathrm{rpm}$ at $4{ }^{\circ} \mathrm{C}$. Finally, the ELISA (Abcam, Cambridge, UK) method was employed to quantify the level of aforementioned mediators.

\section{Statistical analysis}

All statistical analyses were performed using the SPSS software, version 25 (IBM Corp., Armonk, NY). The graphs were drawn using the GraphPad Prism software, version 7 (San Diego, CA, USA). The behavioral data were analyzed by the general linear model (GLM) repeated measures analysis followed by Tukey's post hoc test. Besides, the one-way analysis of variance (ANOVA) test followed by Tukey's post hoc test was employed to evaluate differences of histopathological scorings, pro-inflammatory and antiinflammatory mediators, as well as a7 nAChR and NF-KB genes expression between the groups. The $p$ values $<0.05^{*},<0.01^{\star *}$ and $<0.001^{\star * *}$ were accepted as statistically significant. Comparisons between two groups are reported as mean difference ( $95 \%$ confidence interval), which is abbreviated to MD ( $95 \%$ $\mathrm{Cl})$.

\section{Results}

\section{Locomotion}

According to locomotor assessment using the BBB scale, pre-operation scores were similar between the groups ( $p$ values $>0.05$ ). One day after $\mathrm{SCl}$ induction, locomotor scores declined significantly in all groups except for the sham-operated (Fig. 1A). Repeated measure ANOVA analysis indicated significant effect of time $[F(6,336)=4865, p<0.001]$ and effect of the interaction between treatments and time $[F(42,336)=$ $120.2, p<0.001]$ on locomotor scores during 28 days. Moreover, multiple comparisons using the Tukey as a post-hoc test exhibited the highest locomotor scores in rodents which received $1 \mathrm{mg} / \mathrm{kg}$ of Nicotine [Nicotine ( $1 \mathrm{mg} / \mathrm{kg})$ vs control: MD $(95 \% \mathrm{Cl})=3.321$ ( 2.45 to 4.19$), p<0.001]$. Evidently, the BBB scores of all groups endured significantly lower comparing to sham ( $p$ values $<0.001)$. However, there was no significant difference between Nicotine $1 \mathrm{mg} / \mathrm{kg}$ and Nicotine $1.5 \mathrm{mg} / \mathrm{kg}$ treated groups $(p=0.736)$. Further comparisons between the groups are illustrated in Fig. 1A.

\section{Neuropathic pain}

In order to assess mechanical allodynia, the von Frey method was performed weekly after induction of $\mathrm{SCl}$ and the withdrawal threshold was compared between the groups. Mechanical allodynia in shamoperated group remained intact while there was significant decline in the control group within one week after the surgery [MD $(95 \% \mathrm{Cl})=39.3$ (31.10 to 47.50$), p<0.001]$. The decreasing trend of resistance to mechanical pressure is evident from day 7 of the study (Fig. 1B). Repeated measure analysis revealed significant effect of time $[F(5,280)=1956, p<0.001]$ and also time $\times$ treatment interaction $[F(35,280)=$ $45.47, p<0.001]$, which represents different effectiveness of the administered treatments over time. 
Particularly, Nicotine in doses of $1 \mathrm{mg} / \mathrm{kg}$ and $1.5 \mathrm{mg} / \mathrm{kg}$ could significantly rise the final mechanical threshold compared to the control group ( $p$ values $=0.04$ and 0.01 , respectively). Nevertheless, none of the groups achieved a mechanical resistance similar to the sham. Of note, $1 \mathrm{mg} / \mathrm{kg}$ of Nicotine was selected as the optimal dosage for molecular assessments due to the most locomotor and sensory alleviating response to the administration at this dose.

\section{Spinal cord histopathology}

Figure 2 represents the mean cavity percentage in the spinal cord tissue 28 days after the induction of $\mathrm{SCl}$. The one-way ANOVA test revealed significant difference between the groups $[F(4,25)=101.1, p<$ 0.001]. According to the Tukey post-hoc test, $\mathrm{SCl}$ induction with no treatment significantly increased the mean cavity percentage in the spinal cord tissue comparing to sham-operated group [MD $(95 \% \mathrm{Cl})=28.52$ (23.74 to 33.29), $p$ value < 0.001 ]. However, treating spinal cord injured rats with $1 \mathrm{mg} / \mathrm{kg}$ of Nicotine significantly reduced the cavity percentage compared to the control group during the experiment period $[\mathrm{MD}(95 \% \mathrm{Cl})=8.47(3.70$ to 13.24$), p<0.001]$. Additionally, there was no significant difference between control group and both MLA $+1 \mathrm{mg} / \mathrm{kg}$ Nicotine-treated $(p=0.187)$ and MLA-treated groups $(p=0.628)$.

\section{$\mathrm{M} 1 / \mathrm{M} 2$ expression ratio}

One-way ANOVA analysis followed by the Tukey post-hoc test demonstrated a significant elevation in the expression level of CD86 marker post-SCI $(p<0.001)$, while a significant decline was observed in the expression level of CD206 at 28 days' post-injury (dpi) $(p<0.001)$ (Fig. 3). Interestingly, activation of a7 $\mathrm{nAChR}$ by administration of $1 \mathrm{mg} / \mathrm{kg}$ Nicotine to the injured rats significantly attenuated the expression of M1 marker and in parallel, increased the expression of M2 marker ( $p$ values $<0.001$ ). However, administration of $1.5 \mathrm{mg} / \mathrm{kg}$ of a7 nAChR selective antagonist, MLA, could alter the expression of neither CD86 $(p=0.217)$ nor CD206 $(p=0.266)$ at $28 \mathrm{dpi}$. In summary, Nicotine alleviated the elevated M1/M2 ratio induced by SCI $(p<0.001)$, whereas MLA did not exert any significant effect on classical and alternative macrophage polarization $(p=0.058)$.

\section{M1 downstream markers}

TNF- $\alpha$, IL-1 $\beta$, and IL- 6 are inflammatory, neurodegenerative biomarkers that were measured to evaluate the downstream pathways of $\mathrm{M} 1$ macrophages post- $\mathrm{SCl}$ and the consecutive treatments. Here, it was shown that administration of Nicotine with dosage of $1 \mathrm{mg} / \mathrm{kg}$ could significantly subside the level of TNF-a, IL-1 $\beta$, and IL- 6 in the spinal cord tissue comparing to the control group ( $p$ values < 0.001 ) (Fig. 4). However, single dose of MLA altered none of the aforementioned inflammatory factors (TNF-a: $p=0.071$; IL-1 $\beta$ : $p=0.413$; IL-6: $p=0.366)$. Interestingly, meaningful decline in the expression of IL-1 $\beta$ was observed in the MLA + Nicotine group $(p=0.036)$.

\section{M2 downstream marker}


IL-10 is an anti-inflammatory, neuroprotective biomarker that was measured to assess the downstream pathways of $\mathrm{M} 2$ macrophages in response to $\mathrm{SCl}$ and the following treatments. The one-way ANOVA analysis resulted in different IL-10 level among the groups $[F(4,15)=28.18, p<0.001]$ (Fig. 5). The Tukey post hoc analysis suggested the positive effect of Nicotine on IL-10 level since rodents which received $1 \mathrm{mg} / \mathrm{kg}$ of Nicotine represented higher IL-10 level compared to the control ones $(p=0.010)$.

\section{NF-KB gene expression}

According to Fig. 6, RT-PCR analysis of NF-KB gene was statistically different among the experiment groups $[F(4,15)=23.24, p<0.001]$. It was shown that rodents with $\mathrm{SCl}$ exhibit considerably higher expression level of NF-KB gene in comparison to the sham rats $(p<0.001)$. Compared to the control group, the NF-KB gene level in the Nicotine group was found to be lower $(p=0.009)$, which suggests the direct role of Nicotine in the expression of this gene. Neither MLA $(p=0.753)$ nor MLA + Nicotine $(p=$ 0.772 ) injection was significantly different with the vehicle administration to the control rodents.

\section{a7 nAChR gene expression}

As Fig. 7 represents, RT-PCR analysis of a7 nAChR gene expression demonstrated significant difference between the groups $[F(4,15)=19.07, p<0.001]$. Interestingly, the Tukey post-hoc test indicated that SCI reduces the expression level of a7 nAChR gene at $28 \mathrm{dpi}$ in the spinal cord $(p<0.001)$. Surprisingly, pretreatment with either $1 \mathrm{mg} / \mathrm{kg}$ of Nicotine $(p=0.033)$ or $1.5 \mathrm{mg} / \mathrm{kg}$ of MLA $(p=0.001)$ could relatively reverse the reduced gene expression. In contrast, there was no significant difference in the expression of a7 nAChR between the control group and MLA + Nicotine group $(p=0.993)$.

\section{Discussion}

Our behavioral assessments indicated that pre-treatment with Nicotine could improve secondary complications of $\mathrm{SCl}$ such as locomotor dysfunction and neuropathic pain. The Nicotine alleviating effects appeared to be dose-dependent since $1 \mathrm{mg} / \mathrm{kg}$ of Nicotine had the most notable impact on behavioral recovery, while $3 \mathrm{mg} / \mathrm{kg}$ of the reagent apparently had no significant effect on locomotion and mechanical sensation. Therefore, the optimal dosage $(1 \mathrm{mg} / \mathrm{kg})$ was chosen for molecular assay. Spinal cord injured rats exhibited reduced levels of a7 nAChR gene compared to the sham ones, which was partially reversed by administration of Nicotine. Moreover, Nicotine attenuated the elevated levels of NFKB gene, cavity formation, M1 macrophages, and inflammatory factors while it simultaneously increased M2 macrophages and an anti-inflammatory marker (IL-10) at the injury site. Notably, these alterations were absent in the MLA-treated rodents. Our proposed model regarding the association between $a 7$ $\mathrm{nAChR}$ and neuroinflammation in $\mathrm{SCl}$ is summarized in Fig. 8.

Neuro-inflammatory responses are integrated with secondary $\mathrm{SCl}$, which is initiated in the first 24 hours after primary $\mathrm{SCl}$ and would last chronically. Neuroinflammation plays a critical role in the development of neuropathic pain and locomotor exasperation, induced by SCI [15]. Although various mechanisms 
have been suggested to explain deficiencies after $\mathrm{SCl}$, macrophages activity has been recently regarded as one of the main factors influencing neuroinflammation and axonal survival [16]. In general, it seems that nervous-immune interactions take a remarkable part in the process of secondary $\mathrm{SCl}$, which potentially could lead to significant positive and negative effects on neural survival and neural regeneration. In detail, M1/M2 macrophage polarization paradigm is acting as a seesaw in post-SCI neuroinflammation. The M1 phenotype, recognized as "classic macrophage polarization", produce inflammatory markers (e.g., TNF-a, IL-1 $\beta$, IL-6) that bring about neurotoxic and inflammatory interactions, whereas the M2 phenotype, known as "alternative macrophage polarization", tends to mediate neuroregenerative responses through secretion of anti-inflammatory factors (e.g., IL-10). However, it appears that one-sided shift to $\mathrm{M} 1$ phenotype during the secondary $\mathrm{SCl}$ may facilitate undesirable outcomes varying from excessive inflammatory responses to fibrosis scarring [17]. Previous studies have confirmed this issue, showing that transplantation of M2 macrophages or manipulation of the existing macrophages towards M2 phenotype could lessen neuroinflammation and histopathological abnormalities [4, 18-21]. In this study, we aimed to elucidate the effects of a7 nAChR modification on neuroinflammation and histopathology in an animal model of $\mathrm{SCl}$ considering the role of $\mathrm{M} 1 / \mathrm{M} 2$ macrophage polarization paradigm. To the best of our knowledge, this is the first study that examines this relationship in $\mathrm{SCl}$ setting.

a7 nAChR is a member of nicotinic acetylcholine receptors family and is expressed on both neuronal and non-neuronal cells, including endothelial cells, dendritic cells, macrophages, B cells and T cells. It has been well established that a7 nAChRs are involved in various inflammatory contexts such as sepsis, hemorrhage, rheumatoid arthritis, brain ischemia, myocardial infarction, Alzheimer's disease, schizophrenia, pain and SCI [22-25]. In addition, a remarkable number of studies have explored the effect of $\mathrm{a} 7$ in the extent of traumatic brain injury (TBI), which could be considered a close model to SCl. It has been shown that TBI could result in reduced levels of a7 nAChR in the injured region at both acute and chronic phases after the damage [26]. Besides, Nicotine has been found effective in the improvement of neural loss and behavioral outcomes of subjects with TBI $[27,28]$. The effects of a7 nAChR on regulation of inflammation in TBI models have been supported by observing that vagal nerve stimulation leads to the reduction of pro-inflammatory factors (TNF-a, IL-1 $\beta, I L-6)$ through activation of the receptor $[29,30]$.

Various studies have revealed neuroprotective influences of a7 nAChR on the spinal cord tissue. There is solid evidence concerning the stimulatory effects of a7 nAChR agonists on the level and activity of the receptor [23, 31-34]. Rong et al. has indicated that pre-treatment with a2-adrenoreceptor selective agonist could enhance locomotor recovery after $\mathrm{SCl}$ among rats via amplification of $\mathrm{a} 7 \mathrm{nAChR}$ pathway [32]. Furthermore, it has been reported that a7 nAChR participates in determining the severity of neuropathic pain and mechanical allodynia. In this respect, Loram et al. demonstrated that both systemic and local administrations of $\mathrm{a} 7 \mathrm{nAChR}$ agonist could improve mechanical resistance to the forces, probably via reducing the spinal TNF-a level in a rat model of neuropathic pain [35, 36]. In two distinct studies, Ravikumar et al. showed that both single and multiple administrations of Nicotine, a potent a7 nAChR agonist, attenuate oxidative stress, pro-inflammatory markers, and NF-KB activity while enhance sparring of spinal cord tissue and therefore, the recovery of SCl-induced locomotor dysfunction [11, 37]. Moreover, 
Richardson et al. indicated that nonsmokers with $\mathrm{SCl}$ experience lower grades of neuropathic pain after Nicotine therapy [38]. Furthermore, Lee et al. suggested that Nicotine may reduce inducible nitric oxide synthase (iNOS) protein and mRNA levels, probably due to the activation of a7 nAChR on microglial cells [39]. Herein, we also detected significant improvement in functional and molecular status of the spinal cord injured rodents following administration of $1 \mathrm{mg} / \mathrm{kg}$ of Nicotine, whereas $3 \mathrm{mg} / \mathrm{kg}$ of Nicotine appeared less beneficial. Interestingly, paradoxical effects of Nicotine have been an issue in previous relevant studies and have been related to several features, including dosage, timing and selectivity [25, 40].

Previous studies have addressed the role of a7 nAChR in the orchestration of cholinergic antiinflammatory pathway (CAP), which is a key element in modulation of neuroinflammation through restoring tissue redox homeostasis [41]. In detail, in the process of secondary SCl, neuroinflammation is facilitated when injured cells within the CNS release DAMPs (damage associated molecular patterns) like high mobility group box 1 protein (HMGB1) that bind to toll-like receptors (TLRs) and successively overactivate the NF-KB, which is a crucial modulator in the initiation of inflammatory cascades and macrophages polarization. One of the main reasons for Nicotine therapeutic effects is that there is an opposite interaction between a7 nAChR and NF-KB, presumably via Jak2/STAT3 signaling pathway [41]. In another word, activation of a7 nAChR could reduce neuroinflammation via inhibiting the expression of NF-KB and therefore, reducing inflammatory cytokines production [42, 43]. Interestingly, it has been demonstrated that this pathway is reversible in case of MLA administration. Our results confirm this association as activation of a7 nAChR was accompanied by lower level of NF-KB and subsequently higher TNF-a, IL-1 $\beta$, and IL- 6 levels.

There is mounting evidence that $\mathrm{a} 7 \mathrm{nAChR}$ is associated with microglial activity. For instance, it was shown that pre-conditioning with Nicotine could prevent LPS-induced activated microglial cells from releasing pro-inflammatory cytokines and this effect was faded following the administration of MLA [44]. Several in vivo studies have also pointed to the anti-inflammatory effects of a7 nAChR on microglial cells. In a rat model of focal brain ischemia, Guan et al. discovered that Nicotine regulates microglial proliferation and correspondingly the levels of TNF-a, IL-1 $\beta$ and neural loss even in the acute phase of post-injury and these effects were reversed by pre-treatment with a-bungarotoxin [45]. Several studies of CNS have exclusively discussed the role of $a 7 n A C h R$ in the polarization status of M1/M2 macrophages. In two recent studies of brain ischemia, it was noticed that activation of a7 nAChR is related to the inhibition of NF-KB, reduction of M1 markers (CD68, IL-1 $\beta$, TNF- $\alpha$, IL-6) and lesion volume, elevation of M2 markers (CD206, Arg-1, IL-10), as well as both short-term and long-term behavioral recoveries [6, 7]. Meanwhile, Ma et al. demonstrated that electroacupuncture therapy could enhance axonal survival via activation of a7 nAChR that leads to reduction of M1 markers and simultaneous elevation of M2 markers in a rat model of brain stroke [8].

There has been increasing interest regarding the role of M1/M2 macrophages polarization paradigm in mediation of secondary $\mathrm{SCl}$, as well. A few experiments have targeted this theory to find novel therapeutic options for $\mathrm{SCl}$. The shift of macrophages to the M1 phenotype has been attributed to the activation of 
NF-KB in response to the binding of HMGB1 to TLRs. Results obtained from related investigations are consistent, suggesting higher levels of M1 markers (e.g., CD86) and lower levels of M2 markers (e.g., CD163, CD206) at the injury region of spinal cord. Observing higher concentrations of pro-inflammatory (e.g., TNF- $a$, IL-1 $\beta$, IL-6) and lower concentrations anti-inflammatory (e.g., IL-10) downstream markers confirms this alteration. Therefore, it is not surprising to detect neurodegenerative activities due to the established neuroinflammation $[3,17,46]$. Here, we consistently detected similar results in non-treated $\mathrm{SCl}$ rodents. Additionally, we discovered that elevation of a7 nAChR level due to Nicotine therapy is correlated with shift reversion to M2 phenotype, probably through inhibition of NF-KB. To the best of our knowledge, this is the first study that addresses the association between $\alpha 7 \mathrm{nAChR}$ and macrophages polarization, indicating congruence with previous CNS models.

This study has several limitations. Promotion in $\mathrm{SCl}$ outcomes could be related to either suppression of excessive inflammation through inhibiting M1 polarization or enhancement of axonal repair through stimulating M2 polarization; these two seem undistinguishable in vivo models. However, recent innovative points of view highlight the importance of M1/M2 plasticity, suggesting that there is a dynamic time-dependent interaction between the two mechanisms after SCI [47, 48]. After all, in this study, we concluded that Nicotine could improve SCl outcomes and neuroinflammation possibly via activation of a7 nAChR; however, further clarification of the binding lines between a7 nAChR and macrophages polarization pattern is warranted in SCl setting [49]. On a side note, studies containing larger sample size are recommended to provide better insight into the dose-dependent effects of Nicotine.

\section{Conclusion}

In summary, we indicated that Nicotine could play a promising role in the treatment of $\mathrm{SCl}$ motor and sensory adverse events due to its anti-inflammatory and neuroprotective effects, possibly via increasing the expression of a7 nAChR. However, these effects might vary depending on the content, timing and selectivity. Additionally, it should be noted that NF-KB seems to link neuroinflammation transpiring within secondary $\mathrm{SCl}$ to $\mathrm{a} 7 \mathrm{nAChR}$ as a key modulator of CAP in microglial polarization. Precise blueprints of these effects require further attention.

\section{Abbreviations}

$\mathrm{SCl}$

Spinal cord injury; MLA:Methyllycaconitine; BBB:Basso, Beattie, Bresnahan; a7 nAChR:Alpha-7 nicotinic acetylcholine receptor; NF-KB:Nuclear factor-kappa B; IL:Interleukin; H\&E:Haemotoxylin and Eosin; CNS:Central nervous system; NIH:National institutes of health; PBS:Phosphate buffered saline; IHC:Immunohistochemistry; ELISA:Enzyme-linked immunosorbent assay; DAPI:4',6-Diamidino-2phenylindole; CD:Cluster of differentiation; TNF-a:Tumor necrosis factor-alpha; RT-PCR:Reverse transcription polymerase chain reaction; RNA:Ribonucleic acid; DNA:Deoxyribonucleic acid; GLM:General linear model; GAPDH:Glyceraldehyde-3-phosphate dehydrogenase; MD:Mean difference; Cl:Confidence interval; DPI:Days post injury; TBI:Traumatic brain injury; DAMPS:Damage associated molecular patterns; 
HMGB1:High mobility group box 1; TLR:Toll like receptor; Jak2/STAT3:Janus kinas/ Signal transducer and activator of transcription; CAP:Cholinergic anti-inflammatory pathway.

\section{Declarations}

\section{Conflicts of interest}

Authors have no conflict of interest to disclose.

\section{Acknowledgments}

None

\section{Authors contribution}

AB, KM, ZES, SB, PRSA, SH, MMK, and MK participated in data acquisition, molecular assessments, and preparation of the manuscript. ARD and SMA designed the manuscript, provided the outlines for the presentation of the study, supervised the study process and edited the final manuscript. All authors have reviewed the process of data analysis, writing of the manuscript and approved the final article.

\section{Funding}

This research received no specific grant from any funding agency in the public, commercial, or not-forprofit sectors.

\section{Availability of data and materials}

The datasets used and/or analyzed during this study are available on reasonable request from the corresponding author.

\section{Ethics approval and consent to participate}

The study protocol was executed in agreement with the National Institutes of Health $(\mathrm{NIH})$ Guide for the Care and Use of laboratory animals (NIH publication No. 86-23, Eighth Ed.) and institutional and governmental concerns for animal care and use (Approval ID: IR.TUMS.MEDICINE.REC.1398.922).

\section{Consent for Publication}




\section{References}

1. van den Berg ME, Castellote JM, Mahillo-Fernandez I, de Pedro-Cuesta J. Incidence of spinal cord injury worldwide: a systematic review. Neuroepidemiology. 2010; 34(3):184-92; discussion 92.

2. Anwar MA, Al Shehabi TS, Eid AH. Inflammogenesis of Secondary Spinal Cord Injury. Front Cell Neurosci. 2016; 10(98.

3. Kigerl KA, Gensel JC, Ankeny DP, Alexander JK, Donnelly DJ, Popovich PG. Identification of two distinct macrophage subsets with divergent effects causing either neurotoxicity or regeneration in the injured mouse spinal cord. J Neurosci. 2009; 29(43):13435-44.

4. Shin T, Ahn M, Moon C, Kim S, Sim KB. Alternatively activated macrophages in spinal cord injury and remission: another mechanism for repair? Mol Neurobiol. 2013; 47(3):1011-9.

5. Parri HR, Hernandez CM, Dineley KT. Research update: Alpha7 nicotinic acetylcholine receptor mechanisms in Alzheimer's disease. Biochem Pharmacol. 2011; 82(8):931-42.

6. Han Z, Li L, Wang L, Degos V, Maze M, Su H. Alpha-7 nicotinic acetylcholine receptor agonist treatment reduces neuroinflammation, oxidative stress, and brain injury in mice with ischemic stroke and bone fracture. J Neurochem. 2014; 131(4):498-508.

7. Han Z, Shen F, He Y, Degos V, Camus M, Maze M, Young WL, Su H. Activation of a-7 nicotinic acetylcholine receptor reduces ischemic stroke injury through reduction of pro-inflammatory macrophages and oxidative stress. PLoS One. 2014; 9(8):e105711.

8. Ma Z, Zhang Z, Bai F, Jiang T, Yan C, Wang Q. Electroacupuncture Pretreatment Alleviates Cerebral Ischemic Injury Through a7 Nicotinic Acetylcholine Receptor-Mediated Phenotypic Conversion of Microglia. Front Cell Neurosci. 2019; 13(537.

9. Gensel JC, Kopper TJ, Zhang B, Orr MB, Bailey WM. Predictive screening of M1 and M2 macrophages reveals the immunomodulatory effectiveness of post spinal cord injury azithromycin treatment. Scientific reports. 2017; 7(1):1-10.

10. Moradi K, Golbakhsh M, Haghighi F, Afshari K, Nikbakhsh R, Khavandi MM, Faghani S, Badripour A, Etemadi A, Ashraf-Ganjouei A. Inhibition of phosphodiesterase IV enzyme improves locomotor and sensory complications of spinal cord injury via altering microglial activity: Introduction of Roflumilast as an alternative therapy. International Immunopharmacology. 2020; 86(106743.

11. Ravikumar R, Fugaccia I, Scheff SW, Geddes JW, Srinivasan C, Toborek M. Nicotine attenuates morphological deficits in a contusion model of spinal cord injury. J Neurotrauma. 2005; 22(2):24051.

12. Basso DM, Beattie MS, Bresnahan JC. A sensitive and reliable locomotor rating scale for open field testing in rats. J Neurotrauma. 1995; 12(1):1-21.

13. Bonin RP, Bories C, De Koninck Y. A simplified up-down method (SUDO) for measuring mechanical nociception in rodents using von Frey filaments. Mol Pain. 2014; $10(26$. 
14. Schindelin J, Arganda-Carreras I, Frise E, Kaynig V, Longair M, Pietzsch T, Preibisch S, Rueden C, Saalfeld S, Schmid B. Fiji: an open-source platform for biological-image analysis. Nature methods. 2012; 9(7):676-82.

15. Rice T, Larsen J, Rivest S, Yong VW. Characterization of the early neuroinflammation after spinal cord injury in mice. J Neuropathol Exp Neurol. 2007; 66(3):184-95.

16. Walters ET. Neuroinflammatory contributions to pain after SCl: roles for central glial mechanisms and nociceptor-mediated host defense. Exp Neurol. 2014; 258(48-61.

17. David S, Kroner A. Repertoire of microglial and macrophage responses after spinal cord injury. Nat Rev Neurosci. 2011; 12(7):388-99.

18. Guerrero AR, Uchida K, Nakajima H, Watanabe S, Nakamura M, Johnson WE, Baba H. Blockade of interleukin- 6 signaling inhibits the classic pathway and promotes an alternative pathway of macrophage activation after spinal cord injury in mice. Journal of neuroinflammation. 2012; 9(1):40.

19. Ma S-F, Chen Y-J, Zhang J-X, Shen L, Wang R, Zhou J-S, Hu J-G, Lü H-Z. Adoptive transfer of M2 macrophages promotes locomotor recovery in adult rats after spinal cord injury. Brain, behavior, and immunity. 2015; 45(157-70.

20. Nakajima H, Uchida K, Guerrero AR, Watanabe S, Sugita D, Takeura N, Yoshida A, Long G, Wright KT, Johnson WE. Transplantation of mesenchymal stem cells promotes an alternative pathway of macrophage activation and functional recovery after spinal cord injury. Journal of neurotrauma. 2012; 29(8):1614-25.

21. Ren $Y$, Young W. Managing inflammation after spinal cord injury through manipulation of macrophage function. Neural Plast. 2013; 2013(945034.

22. Cai B, Chen F, Ji Y, Kiss L, de Jonge WJ, Conejero-Goldberg C, Szabo C, Deitch EA, Ulloa L. Alpha7 cholinergic-agonist prevents systemic inflammation and improves survival during resuscitation. $\mathrm{J}$ Cell Mol Med. 2009; 13(9b):3774-85.

23. Bertrand D, Lee CH, Flood D, Marger F, Donnelly-Roberts D. Therapeutic Potential of alpha7 Nicotinic Acetylcholine Receptors. Pharmacol Rev. 2015; 67(4):1025-73.

24. Bencherif M, Narla ST, Stachowiak MS. Alpha7 neuronal nicotinic receptor: a pluripotent target for diseases of the central nervous system. CNS Neurol Disord Drug Targets. 2014; 13(5):836-45.

25. Bencherif M, Lippiello PM, Lucas R, Marrero MB. Alpha7 nicotinic receptors as novel therapeutic targets for inflammation-based diseases. Cell Mol Life Sci. 2011; 68(6):931-49.

26. Kelso ML, Oestreich JH. Traumatic brain injury: central and peripheral role of alpha7 nicotinic acetylcholine receptors. Curr Drug Targets. 2012; 13(5):631-6.

27. Verbois SL, Hopkins DM, Scheff SW, Pauly JR. Chronic intermittent nicotine administration attenuates traumatic brain injury-induced cognitive dysfunction. Neuroscience. 2003; 119(4):1199208.

28. Guseva MV, Hopkins DM, Scheff SW, Pauly JR. Dietary choline supplementation improves behavioral, histological, and neurochemical outcomes in a rat model of traumatic brain injury. J Neurotrauma. 2008; 25(8):975-83. 
29. Kox M, Pompe JC, Pickkers P, Hoedemaekers CW, van Vugt AB, van der Hoeven JG. Increased vagal tone accounts for the observed immune paralysis in patients with traumatic brain injury. Neurology. 2008; 70(6):480-5.

30. Wang H, Yu M, Ochani M, Amella CA, Tanovic M, Susarla S, Li JH, Wang H, Yang H, Ulloa L, et al. Nicotinic acetylcholine receptor alpha7 subunit is an essential regulator of inflammation. Nature. 2003; 421(6921):384-8.

31. Akaike A, Takada-Takatori Y, Kume T, Izumi Y. Mechanisms of neuroprotective effects of nicotine and acetylcholinesterase inhibitors: role of alpha4 and alpha7 receptors in neuroprotection. $\mathrm{J} \mathrm{Mol}$ Neurosci. 2010; 40(1-2):211-6.

32. Rong H, Zhao Z, Feng J, Lei Y, Wu H, Sun R, Zhang Z, Hou B, Zhang W, Sun Y. The effects of dexmedetomidine pretreatment on the pro-and anti-inflammation systems after spinal cord injury in rats. Brain, Behavior, and Immunity. 2017; 64(195-207.

33. Costantini A, Viola N, Berretta A, Galeazzi R, Matacchione G, Sabbatinelli J, Storci G, De Matteis S, Butini L, Rippo MR, et al. Age-related M1/M2 phenotype changes in circulating monocytes from healthy/unhealthy individuals. Aging (Albany NY). 2018; 10(6):1268-80.

34. Jonnala RR, Buccafusco JJ. Relationship between the increased cell surface a7 nicotinic receptor expression and neuroprotection induced by several nicotinic receptor agonists. Journal of neuroscience research. 2001; 66(4):565-72.

35. Loram LC, Harrison JA, Chao L, Taylor FR, Reddy A, Travis CL, Giffard R, Al-Abed Y, Tracey K, Maier SF, Watkins LR. Intrathecal injection of an alpha seven nicotinic acetylcholine receptor agonist attenuates gp120-induced mechanical allodynia and spinal pro-inflammatory cytokine profiles in rats. Brain Behav Immun. 2010; 24(6):959-67.

36. Loram LC, Taylor FR, Strand KA, Maier SF, Speake JD, Jordan KG, James JW, Wene SP, Pritchard RC, Green $\mathrm{H}$. Systemic administration of an alpha-7 nicotinic acetylcholine agonist reverses neuropathic pain in male Sprague Dawley rats. The Journal of Pain. 2012; 13(12):1162-71.

37. Ravikumar R, Flora G, Geddes JW, Hennig B, Toborek M. Nicotine attenuates oxidative stress, activation of redox-regulated transcription factors and induction of proinflammatory genes in compressive spinal cord trauma. Brain Res Mol Brain Res. 2004; 124(2):188-98.

38. Richardson EJ, Ness TJ, Redden DT, Stewart CC, Richards JS. Effects of nicotine on spinal cord injury pain vary among subtypes of pain and smoking status: results from a randomized, controlled experiment. J Pain. 2012; 13(12):1206-14.

39. Lee MY, Chen L, Toborek M. Nicotine attenuates iNOS expression and contributes to neuroprotection in a compressive model of spinal cord injury. J Neurosci Res. 2009; 87(4):937-47.

40. Oloris SC, Frazer-Abel AA, Jubala CM, Fosmire SP, Helm KM, Robinson SR, Korpela DM, Duckett MM, Baksh S, Modiano JF. Nicotine-mediated signals modulate cell death and survival of T lymphocytes. Toxicology and applied pharmacology. 2010; 242(3):299-309.

41. Egea J, Buendia I, Parada E, Navarro E, Leon R, Lopez MG. Anti-inflammatory role of microglial alpha7 nAChRs and its role in neuroprotection. Biochem Pharmacol. 2015; 97(4):463-72. 
42. Neumann S, Shields NJ, Balle T, Chebib M, Clarkson AN. Innate Immunity and Inflammation PostStroke: An alpha7-Nicotinic Agonist Perspective. Int J Mol Sci. 2015; 16(12):29029-46.

43. de Jonge WJ, van der Zanden EP, The FO, Bijlsma MF, van Westerloo DJ, Bennink RJ, Berthoud HR, Uematsu S, Akira S, van den Wijngaard RM, Boeckxstaens GE. Stimulation of the vagus nerve attenuates macrophage activation by activating the Jak2-STAT3 signaling pathway. Nat Immunol. 2005; 6(8):844-51.

44. Shytle RD, Mori T, Townsend K, Vendrame M, Sun N, Zeng J, Ehrhart J, Silver AA, Sanberg PR, Tan J. Cholinergic modulation of microglial activation by alpha 7 nicotinic receptors. J Neurochem. 2004; 89(2):337-43.

45. Guan YZ, Jin XD, Guan LX, Yan HC, Wang P, Gong Z, Li SJ, Cao X, Xing YL, Gao TM. Nicotine inhibits microglial proliferation and is neuroprotective in global ischemia rats. Mol Neurobiol. 2015; 51(3):1480-8.

46. Gensel JC, Zhang B. Macrophage activation and its role in repair and pathology after spinal cord injury. Brain Res. 2015; 1619(1-11.

47. Kong X, Gao J. Macrophage polarization: a key event in the secondary phase of acute spinal cord injury. J Cell Mol Med. 2017; 21(5):941-54.

48. David S, Greenhalgh AD, Kroner A. Macrophage and microglial plasticity in the injured spinal cord. Neuroscience. 2015; 307(311-8.

49. Zhang Q, Lu Y, Bian H, Guo L, Zhu H. Activation of the a7 nicotinic receptor promotes lipopolysaccharide-induced conversion of M1 microglia to M2. Am J Transl Res. 2017; 9(3):971-85.

\section{Figures}



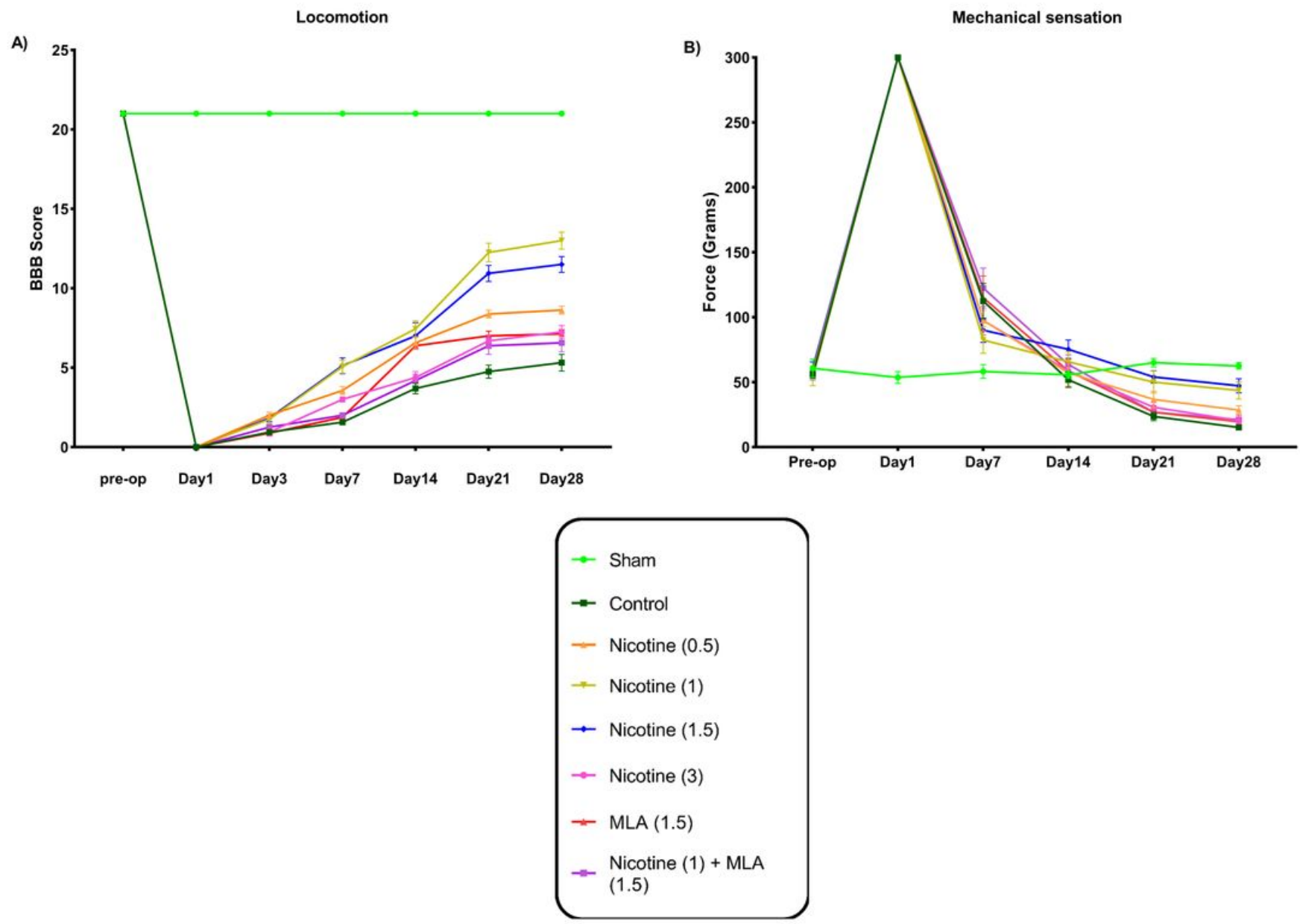

\section{Figure 1}

Repeated measure for comparison of the effects of the treatment groups on motor and sensory complications of $\mathrm{SCl}$ during the study period. A) BBB locomotor scores of the groups during 28-days period. Values are represented as the mean \pm standard error mean (SEM). B) Von Frey scores for the assessment of the mean resistance of the study groups to mechanical pressure. Values are represented as the mean \pm SEM. 

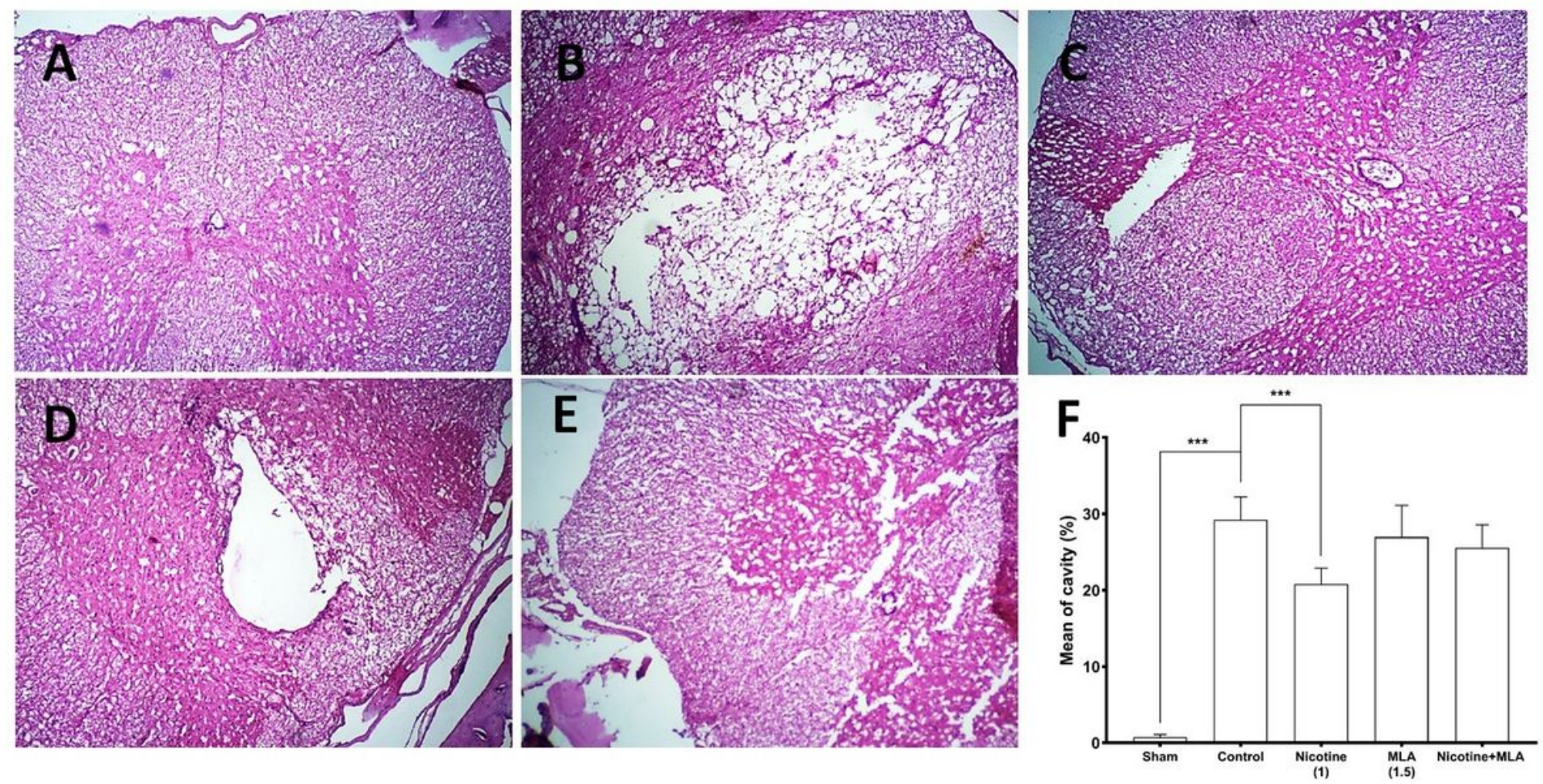

\section{Figure 2}

Histopathological pictures of the groups, produced by H\&E staining of spinal cord sections at the injury region after a period of 28 days: (A) sham, (B) control, (C) Nicotine (1 mg/kg), (D) MLA (1.5 mg/kg), (E) Nicotine $(1 \mathrm{mg} / \mathrm{kg})+$ MLA $(1.5 \mathrm{mg} / \mathrm{kg})$. (F) analyzes the differences of cavity formation between the groups (mean \pm standard deviation). The cavity percentage was significantly lower in the sham group compared to the others. Significant differences with the control group were shown in the graph. $* \star \star: p<$ 0.001 . 


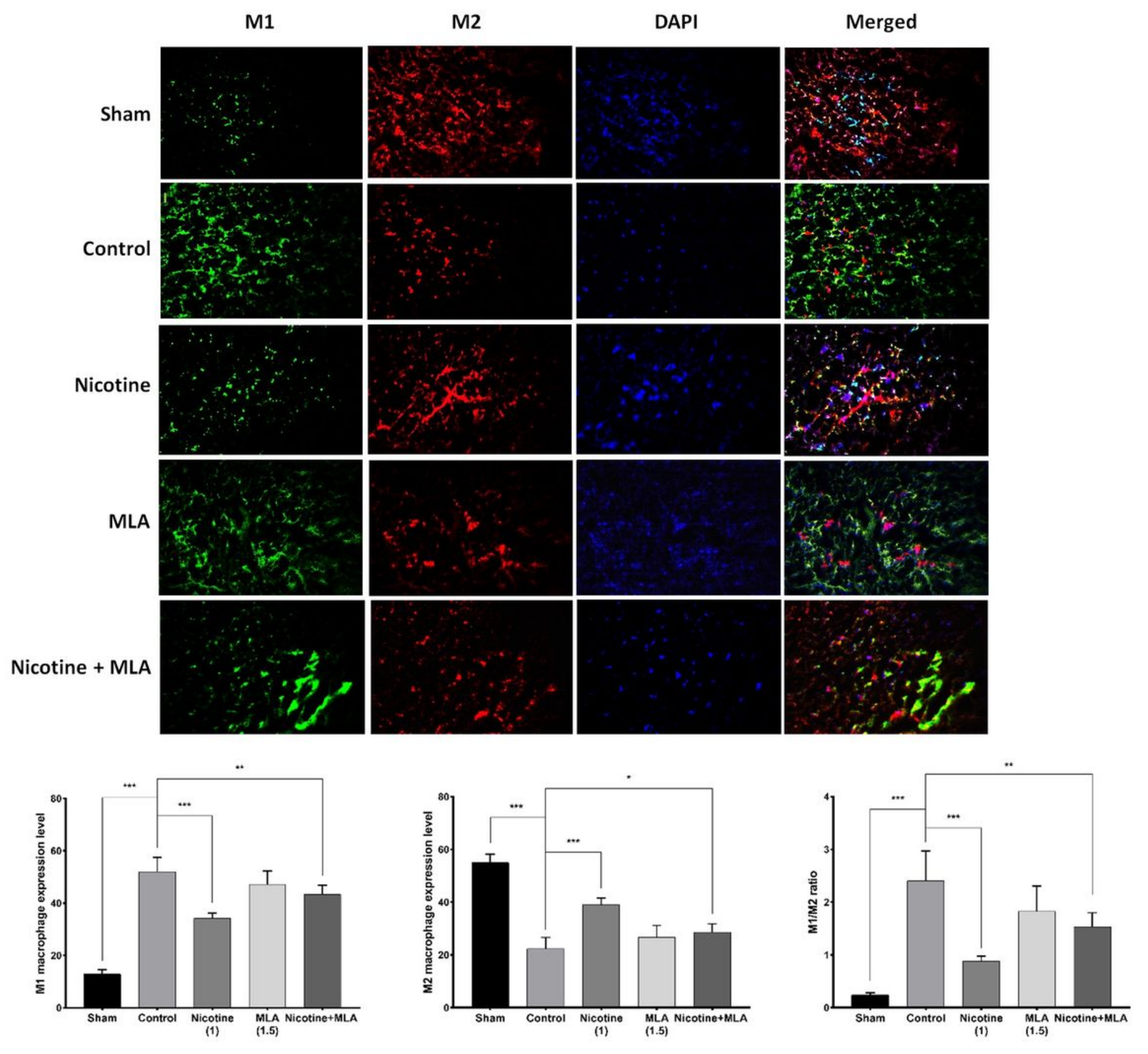

Figure 3

Immunohistochemical staining of M1 and M2 macrophages in the injury site of spinal cord. Bar charts depict the expression of $\mathrm{M} 1$ and $M 2$, as well as the relative $M 1 / M 2$ ratio in the study groups (mean \pm standard deviation). *: $0.01<p<0.05 ; * \star: 0.01<p<0.001 ; * \star *: p<0.001$. 



Figure 4

Comparison of pro-inflammatory factors, including TNF-a, IL- $1 \beta$, and IL- 6 between the groups 28 days after $\mathrm{SCl}$. Values are represented as the mean \pm standard deviation. Significant differences with the control group are shown. *: $0.01<p<0.05 ; * \star *$ : $<<0.001$.



Figure 5 
Comparison of IL-10 level between the groups. Values are reported as the mean \pm standard deviation. Significant differences with the control group are indicated. $*$ : $0.01<p<0.05 ; * \star *: p<0.001$.

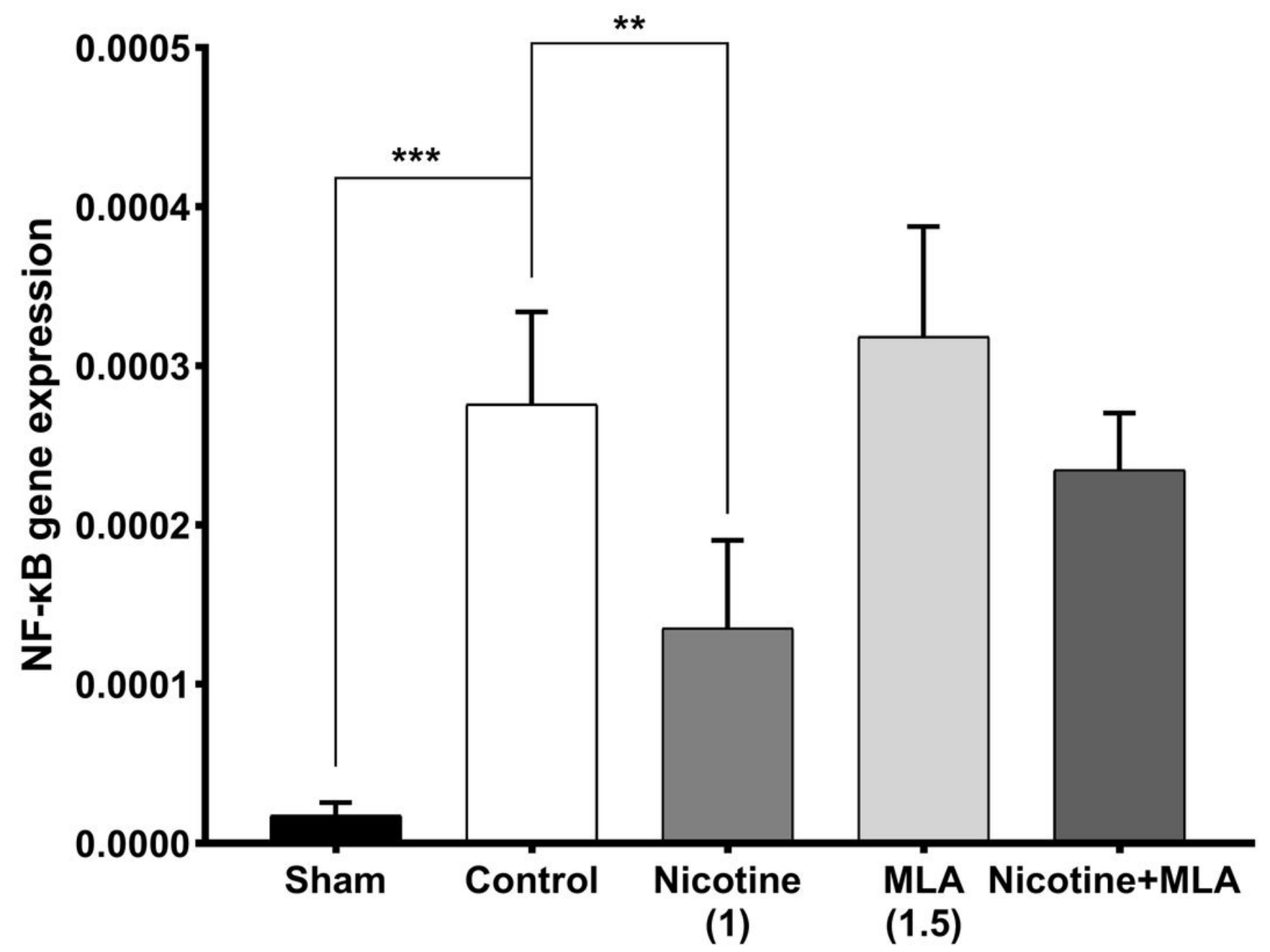

Figure 6

Nuclear factor kappa b (NF-KB) gene expression in the study groups. Significant differences with the control animals are manifested. $* *: 0.01<p<0.001 ; * \star *: p<0.001$. 


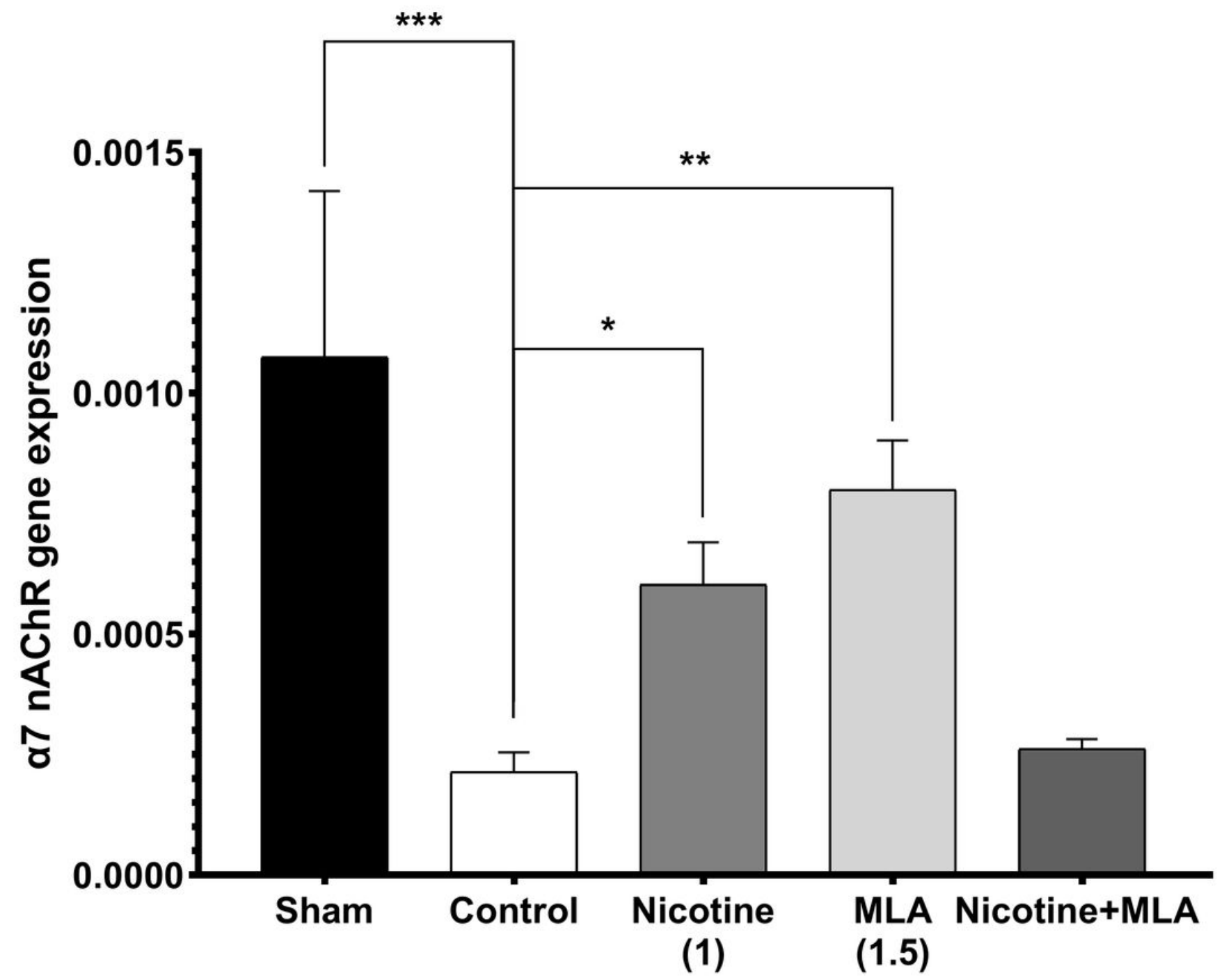

Figure 7

Alpha-7 nicotinic acetylcholine receptor ( $\mathrm{a} 7 \mathrm{nAChR}$ ) gene expression in the study groups at $28 \mathrm{dpi}$. Significant differences with the control group are marked. $*$ : $p<0.05 ; * \star: 0.01<p<0.001 ; * \star \star: p<0.001$. 


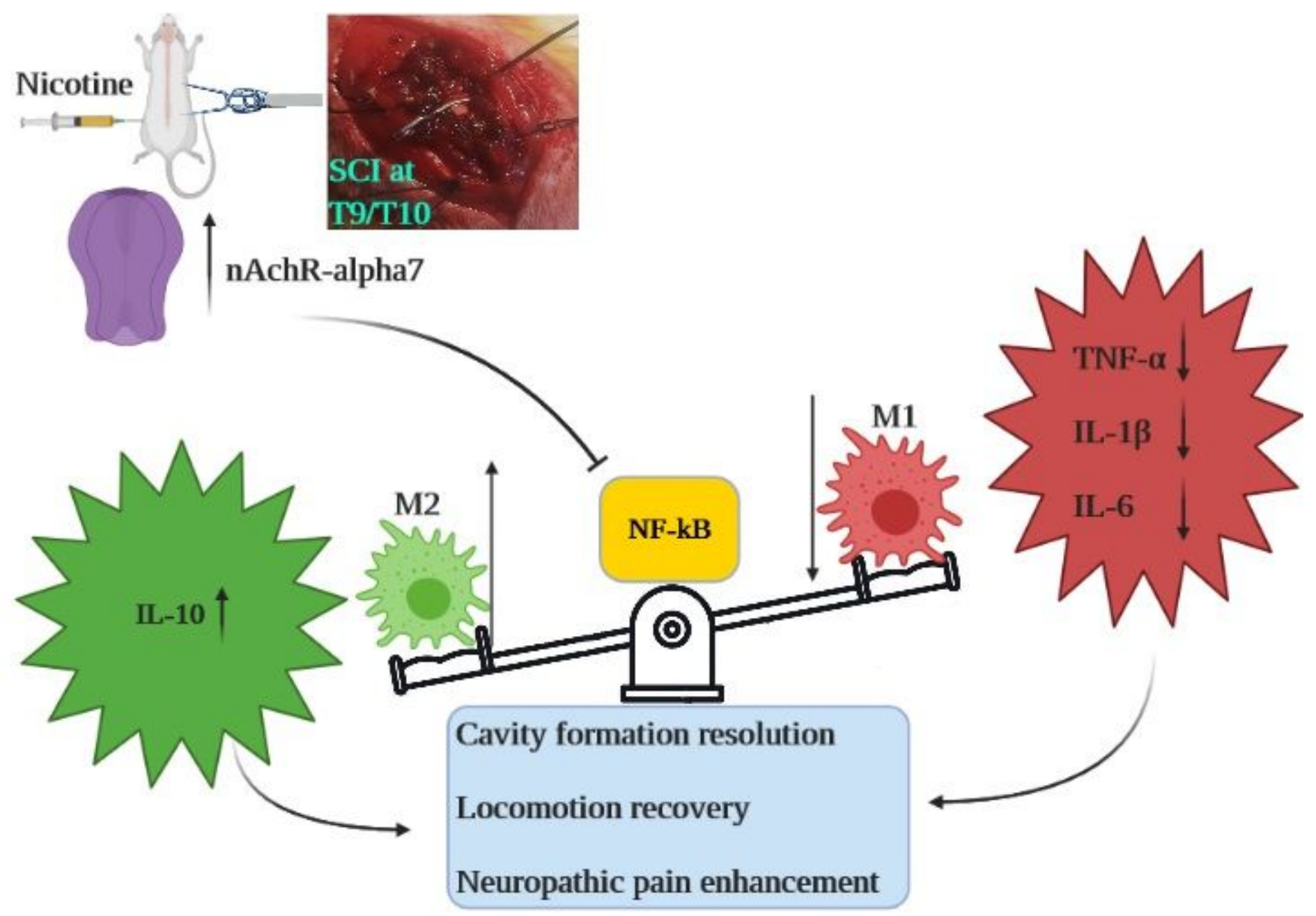

Figure 8

Cavity formation, M1 macrophages, and inflammatory factors 